\title{
Association of the CYP4F2 rs2108622 genetic polymorphism with hypertension: a meta-analysis
}

\author{
X.-H. Luo ${ }^{1}$, G.-R. Li ${ }^{2}$ and H.-Y. Li ${ }^{1}$ \\ ${ }^{1}$ Department of Geriatrics, the Fifth Affiliated Hospital of Zhengzhou University, \\ Zhengzhou, China \\ ${ }^{2}$ Railway Vocational and Technical College of Zhengzhou, Zhengzhou, China \\ Corresponding author: H.-Y. Li \\ E-mail: liuhongyun971@163.com \\ Genet. Mol. Res. 14 (4): 15133-15139 (2015) \\ Received January 28, 2015 \\ Accepted May 18, 2015 \\ Published November 25, 2015 \\ DOI http://dx.doi.org/10.4238/2015.November.25.1
}

\begin{abstract}
Previous case-control studies on the relationship between the CYP4F2 gene rs2108622 polymorphism and hypertension have produced contrasting results. In this study, we aimed to further evaluate the relationship between the $C Y P 4 F 2$ gene rs2108622 polymorphism and hypertension. We selected four case-control studies related to the CYP4F2 gene rs2108622 polymorphism and hypertension by searching PubMed, EMBase, the Chinese Biomedical Literature Database, and the Wanfang database. We utilized the Cochran $Q$-test and the $I^{2}$ index to measure the heterogeneity across studies. To merge the odds ratio (OR) and the $95 \%$ confidence interval $(95 \% \mathrm{CI})$, we utilized the fixed and random-effect models during the analyses. The present study included 1878 patients with hypertension and 1512 healthy control subjects. By meta-analysis, we did not find any association of the CYP4F2 gene rs2108622 polymorphism with hypertension in either genotype or allele distribution $[\mathrm{AA}+\mathrm{AG}$ vs $\mathrm{GG}$ : $\mathrm{OR}=1.18,95 \% \mathrm{CI}(0.91-1.54), \mathrm{P}=0.21$; $\mathrm{GG}+\mathrm{AG} v s \mathrm{AA}: \mathrm{OR}=0.91,95 \% \mathrm{CI}(0.80-1.05), \mathrm{P}=0.20 ;$ A allele $v s$ $\mathrm{G}$ allele: $\mathrm{OR}=1.04,95 \% \mathrm{CI}(0.93-1.16), \mathrm{P}=0.53]$. We concluded that
\end{abstract}


the CYP4F2 gene rs2108622 polymorphism was not associated with hypertension.

Key words: Hypertension; CYP4F2; Gene polymorphism; Meta-analysis

\section{INTRODUCTION}

Hypertension is the most frequently diagnosed cardiovascular disease in the world (Karpinos et al., 2013). Recently, hypertension has been recognized as a complex multifactorial disease resulting from the interactions between many genetic and environmental factors (Bener et al., 2013; Zhang et al., 2013). Numerous genes have been reported to be associated with hypertension, including the $A C E$ (Borah et al., 2012), CYP1A1 (Demirdöğen et al., 2013), and CYP19A1 genes (Ziv-Gal et al., 2012). However, the genetic polymorphisms in these genes only explain a small fraction of hypertension.

20-Hydroxyeicosatetraenoic acid (20-HETE) is a critical factor for the regulation of vascular tone in renal, cerebral, coronary, and skeletal muscle arterioles, as well as in pulmonary circulation (Roman, 2002; Miyata et al., 2005; Yousif et al., 2009). 20-HETE is a potent vasoconstrictor and can induce the myogenic constriction of cerebral blood vessels (Miyata et al., 2005; Gebremedhin et al., 2000, 2008). Arachidonic acid (AA), a major membrane fatty acid, is metabolized by cytochrome (CYP) P450 enzymes in cerebral arteries to 20-HETE (Harder et al., 1994). Recent studies have indicated that 20-HETE plays an important role in the pathogenesis of ischemic stroke (Deng et al., 2010).

The CYP4F2 subfamily of CYP450 enzymes in turn is involved in the metabolism of 20-HETE (Lasker et al., 2000). The CYP4F2 gene is located on chromosome 19p13.12. It is comprised of 13 exons and 12 introns, and encodes a hydroxylase that catalyzes the metabolism of AA, leukotriene B4, and tocopherol (Kikuta et al., 2000; Sontag and Parker, 2002). Functional studies have shown that a single nucleotide polymorphism (G-A), resulting in a methionine to valine substitution at amino acid 433 (V433M, rs2108622) of CYP4F2, leads to a protein with significantly reduced AA metabolizing activity. Some recent studies have found an association between the G-A polymorphism at nucleotide position 1347 and hypertension (Fu et al., 2008a; Ward et al., 2008). However, other published reports did not reach the same conclusion. This contradiction may potentially be due to inadequate sample sizes or patient selection, or to the ethnicities of the populations studied. Furthermore, a single study may be insufficient to detect a possible small effect of the polymorphism on hypertension. Meta-analysis is a useful method for investigating the associations between diseases and risk factors because it uses a quantitative approach to combine the results of multiple different studies on a single topic, thus potentially providing more rigorous conclusions (Duval and Tweedie, 2000; Higgins et al., 2003). Considering the extensive role of CYP4F2 is predicted to play in the pathogenesis of hypertension, we performed a meta-analysis on all eligible case-control studies to better estimate the association between the rs 2108622 polymorphism and hypertension risk.

\section{MATERIAL AND METHODS}

\section{Literature collation and screening}

To identify all the articles that explored the association of CYP4F2 polymorphisms 
with hypertension risk, we conducted a computerized literature search of PubMed, EMBase, the Chinese Biomedical Literature Database, and the Wanfang database using the terms "hypertension (Mesh)" and "CYP4F2," "polymorphism or SNP or genotype or rs2108622", without any restriction on language or publication year. By means of online retrieval and literature review, references obtained using the above-mentioned databases were manually reviewed again to ensure that no relevant studies were missed.

The inclusion criteria for the present study were as follows: 1) independently published case-control or cohort studies on the relationship between the CYP4F2 polymorphism and hypertension; 2) similar themes and methods across studies; 3 ) sufficient information had to be provided to calculate the odds ratio (OR) with $95 \%$ confidence interval (CI); 4) a control group genotype distribution consistent with Hardy-Weinberg equilibrium (HWE). Accordingly, the following exclusion criteria were also used: 1) abstracts and reviews; 2) studies in which the genotype frequencies were not reported; and 3) repeated or overlapped publications. For studies with the same case series by the same authors, the most recently published studies or the studies with the largest numbers of subjects were included.

\section{Quality assessment and data extraction}

Two reviewers (X.H.L. and G.R.L.) independently evaluated the studies and extracted the data using a standard approach according to the inclusion criteria listed above. Discrepancies were resolved through discussion. We utilized the Cochrane Handbook 5.2 quality evaluation criteria to assess the methodological quality of studies included.

For each study we abstracted the first author's last name, year of publication, ethnicity of participants, numbers of cases and controls, and frequency of insertion or deletion genotypes.

\section{Statistical analysis}

For each case-control study, the HWE of genotypes in the control group was assessed by using the Pearson chi-squared test. The OR and 95\%CI were used to assess the strength of the association between the rs 2108622 polymorphism and hypertension risk. We performed the current meta-analysis utilizing the RevMan 5.2 statistical software, which was provided by the Cochrane Collaboration (London, UK). We utilized the $Q$-test and the $I^{2}$ index to examine the heterogeneity across studies. In the current study, we selected the fixed effects model to merge the ORs. Analysis of sensitivity included the difference of point estimation and confidence intervals of the combined effects value of different models to observe whether it changed the result. To test the publication bias, we utilized RevMan 5.2 to make the funnel plot. $\mathrm{P}<0.05$ was considered as a significant difference.

\section{RESULTS}

\section{Study identification}

Preliminary database screening detected 132 published items from the literature; 121 items were excluded because of lack of $C Y P 4 F 2$ gene polymorphisms, only containing gene expression analysis, or not being relevant to hypertension. An additional 7 studies were excluded because of being either review papers or duplicated publications. Therefore, a total of 
4 reports from the literature (Fu et al., 2008b; Zhang et al., 2010; Fan et al., 2011; Li et al., 2013), with a total of 1878 patients with hypertension and 1512 healthy control subjects, were included in this research. The characteristics of these studies are shown in Table 1.

$$
\text { Table 1. Characteristics of included studies. }
$$

\begin{tabular}{|c|c|c|c|c|c|c|c|c|c|c|c|c|c|c|}
\hline \multirow[t]{3}{*}{ Studies } & \multirow[t]{3}{*}{ Year } & \multirow[t]{3}{*}{ Race } & \multicolumn{6}{|c|}{ Case } & \multicolumn{6}{|c|}{ Control } \\
\hline & & & \multirow[t]{2}{*}{$\mathrm{N}$} & \multicolumn{3}{|c|}{ Genotype (n) } & \multicolumn{2}{|c|}{ allele } & \multirow[t]{2}{*}{$\mathrm{N}$} & \multicolumn{3}{|c|}{ Genotype (n) } & \multicolumn{2}{|c|}{ allele } \\
\hline & & & & $\overline{\mathrm{AA}}$ & $\mathrm{AG}$ & GG & $\mathrm{A}$ & $\mathrm{G}$ & & $\mathrm{AA}$ & $\mathrm{AG}$ & GG & $\mathrm{A}$ & $\mathrm{G}$ \\
\hline Fu ZY & 2008 & Chinese & 249 & 32 & 74 & 143 & 138 & 360 & 208 & 19 & 91 & 128 & 129 & 347 \\
\hline Zhang LX & 2010 & Chinese & 189 & 12 & 55 & 122 & 79 & 299 & 187 & 12 & 70 & 105 & 94 & 280 \\
\hline Fan $\mathrm{CH}$ & 2011 & Chinese & 680 & 44 & 226 & 410 & 314 & 1046 & 647 & 35 & 209 & 403 & 279 & 1015 \\
\hline Li M & 2013 & Chinese & 760 & 61 & 296 & 403 & 418 & 1102 & 470 & 35 & 162 & 273 & 232 & 708 \\
\hline
\end{tabular}

\section{Quantitative synthesis}

The results from meta-analysis of the association between hypertension risk and a $C Y P 4 F 2$ gene polymorphism in 4 case-control studies are shown in Figures 1 to 3. No significant association between $C Y P 4 F 2$ rs2108622 polymorphism and susceptibility to hypertension was identified in any of the genetic models examined [AA+AG vs GG: OR $=1.18,95 \% \mathrm{CI}$ (0.91-1.54), $\mathrm{P}=0.21$ (Figure 1); $\mathrm{GG}+\mathrm{AG}$ vs $\mathrm{AA}: \mathrm{OR}=0.91,95 \% \mathrm{CI}(0.80-1.05), \mathrm{P}=0.20$ (Figure 2); A allele $v s \mathrm{G}$ allele: $\mathrm{OR}=1.04,95 \% \mathrm{CI}(0.93-1.16), \mathrm{P}=0.53$ ] (Figure 3).

\begin{tabular}{|c|c|c|c|c|c|c|}
\hline Study or Subaroup & $\begin{array}{c}\text { Case } \\
\text { Events Total }\end{array}$ & $\begin{array}{l}\text { Control } \\
\text { Events Total }\end{array}$ & Weight & $\begin{array}{c}\text { Odds Ratio } \\
\text { M-H, Fixed, } 95 \% \mathrm{Cl}\end{array}$ & Year & $\begin{array}{c}\text { Odds Ratio } \\
\text { M-H, Fixed, } 95 \% \mathrm{Cl}\end{array}$ \\
\hline Fu ZY 2008 & $32 \quad 249$ & $19 \quad 208$ & $17.6 \%$ & $1.47[0.80,2.67]$ & 2000 & \\
\hline Zhang LX2010 & 189 & 12187 & $11.0 \%$ & $0.99[0.43,2.26]$ & 2010 & \\
\hline Fan $\mathrm{CH} 2011$ & 680 & $\begin{array}{ll}35 & 647\end{array}$ & $32.7 \%$ & $1.21[0.77,1.91]$ & 2011 & \\
\hline Li M 2013 & 61760 & $35 \quad 470$ & $38.7 \%$ & $1.08[0.70,1.67]$ & 2013 & \\
\hline Total (95\% Cl) & 1878 & 1512 & $100.0 \%$ & $1.18[0.91,1.54]$ & & \\
\hline Total events & 149 & 101 & & & & \\
\hline $\begin{array}{l}\text { Heterogeneity: } \mathrm{Ch}^{2} \\
\text { Test for overall effec }\end{array}$ & $\begin{array}{l}0.84, \mathrm{df}=3(\mathrm{P}= \\
Z=1.24(P=0.2\end{array}$ & $\begin{array}{l}0.84 ; 1^{2}=0 \% \\
\text { 1) }\end{array}$ & & & & 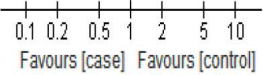 \\
\hline
\end{tabular}

Figure 1. Forest plot of hypertension risk and CYP4F2 gene polymorphism in a dominant model (AA+AG $v s \mathrm{GG})$, the horizontal lines correspond to the study-specific OR and $95 \%$ CI, respectively. The area of the squares reflects the study-specific weight. The diamond represents the pooled results of OR and $95 \% \mathrm{CI}$.

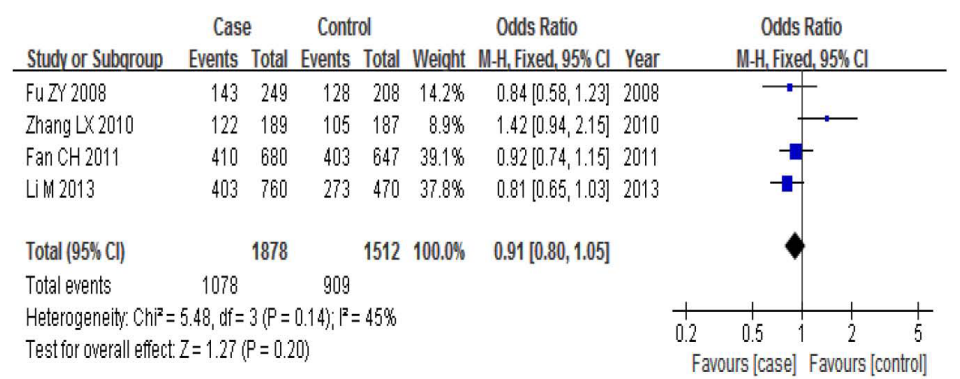

Figure 2. Forest plot of hypertension risk and CYP4F2 gene polymorphism in a recessive model (AA+AG $v s \mathrm{GG}$ ), the horizontal lines correspond to the study-specific OR and $95 \% \mathrm{CI}$, respectively. The area of the squares reflects the study-specific weight. The diamond represents the pooled results of OR and 95\%CI. 


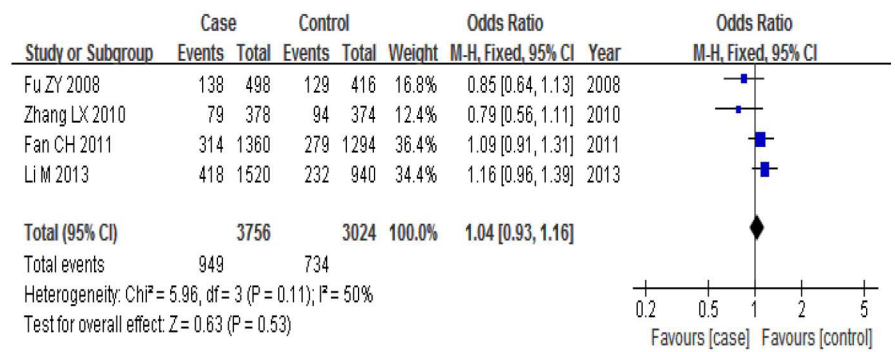

Figure 3. Forest plot of hypertensionriskand CYP4F2 gene polymorphism in anallele model (A allele $v_{s} \mathrm{G}$ allele), the horizontal lines correspond to the study-specific OR and 95\%CI, respectively. The area of the squares reflects the study-specific weight. The diamond represents the pooled results of OR and $95 \% \mathrm{CI}$.

\section{Publication bias analysis}

We utilized the RevMan 5.2 software to analyze the publication bias; that is, the likelihood that more published studies would reflect positive outcomes (association) than negative outcomes. The funnel plots (Figure 4) show that the points are evenly distributed and symmetrical, and most lie within the $95 \%$ CI. The shapes of the funnel plots themselves also showed no obvious asymmetry, and the subsequent result of the Egger test did not show statistical evidence for publication bias. Together, these observations indicate that there is no publication bias, and that the result of the meta-analysis is credible.

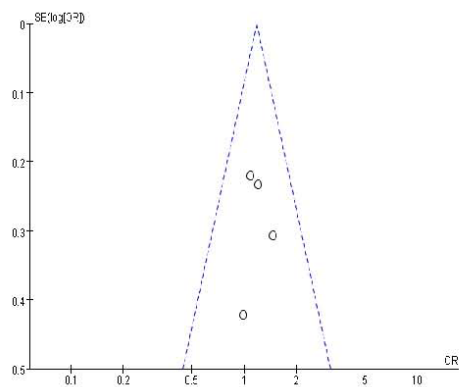

A

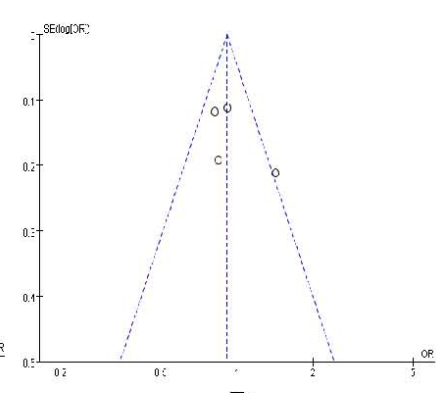

B

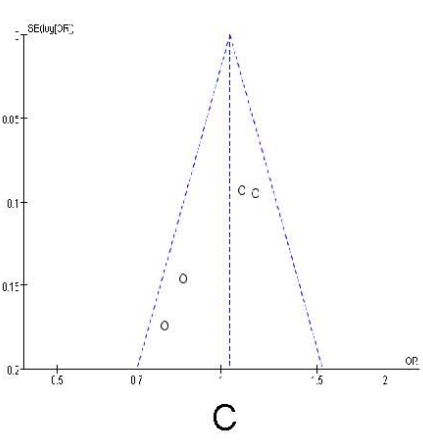

Figure 4. Funnel plot for publication bias test. Each point represents a separate study for the indicated association. Log OR represents the natural logarithm of OR. The vertical line represents the mean effect size.

\section{DISCUSSION}

In the present study, we performed a meta-analysis to evaluate the association of the CYP4F2 gene rs2108622 polymorphism with hypertension. Several previous case-control studies have been conducted to determine whether such an association exists (Fu et al., 2008a; Zhang et al., 2010; Fan et al., 2011; Li et al., 2013); however, the results were inconclusive. In this meta-analysis, we found no evidence that CYP4F2 rs2108622 was associated with hypertension. This result could be explained by several factors. On the one hand, the etiology of hypertension is complex and the SNPs in CYP4F2 may interact with other risk factors, such as smoking, not assessed in these studies. On the other hand, the polymorphisms in CYP4F2 
may have a complex interactive effect to increase both CYP4F2 activity and hypertension risk. The present meta-analysis, which included 4 independent case-control studies, has shown that the CYP4F2 gene rs2108622 polymorphism was not associated with an enhanced risk of hypertension. However, there is still a need for further research on this topic, including screening for etiological relationships between the other functional polymorphic sites in the $C Y P 4 F 2$ gene locus, and the susceptibility toward hypertension.

\section{REFERENCES}

Bener A, Darwish S, Al-Hamaq AO, Mohammad RM, et al. (2013). Association of PPAR $\gamma 2$ gene variant Pro12Ala polymorphism with hypertension and obesity in the aboriginal Qatari population known for being consanguineous. Appl. Clin. Genet. 6: 103-111.

Borah PK, Shankarishan P, Hazarika NC, and Mahanta J (2012). Hypertension subtypes and angiotensin converting enzyme (ACE) gene polymorphism in Indian population. J. Assoc. Physicians India 60: 11, 15-17.

Demirdöğen BC, Adali AÇ, Bek S, Demirkaya Ş, et al. (2013). Cytochrome P4501A1 genotypes and smoking- and hypertension-related ischemic stroke risk. Hum. Exp. Toxicol. 32: 483-491.

Deng S, Zhu G, Liu F, Zhang H, et al. (2010). CYP4F2 gene V433M polymorphism is associated with ischemic stroke in the male Northern Chinese Han population. Prog. Neuropsychopharmacol. Biol. Psychiatry 34: 664-668.

Duval S and Tweedie R (2000). Trim and fill: a simple funnel-plot-based method of testing and adjusting for publication bias in meta-analysis. Biometrics 56: 455-463.

Fan $\mathrm{CH}, \mathrm{He} \mathrm{QF}, \mathrm{Yu}$ M, Chen ZK, et al. (2011). Association between genetic polymorphisms of CYP4F2 and susceptibility of essential hypertension. Zhejiang Med. 33: 1732-1734.

Fu ZY, Ma YT, and Yang YN (2008a). Association between the SNPs of human CYP4F2 gene and essential hypertension in Japan. J. Xinjiang Med. Univ. 31: 1123-1127 (In Chinese).

Fu Z, Nakayama T, Sato N, Izumi Y, et al. (2008b). Haplotype-based case-control study of the human CYP4F2 gene and essential hypertension in Japanese subjects. Hypertens. Res. 31: 1719-1726.

Gebremedhin D, Lange AR, Lowry TF, Taheri MR, et al. (2000). Production of 20-HETE and its role in autoregulation of cerebral blood flow. Circ. Res. 87: 60-65.

Gebremedhin D, Yamaura K, and Harder DR (2008). Role of 20-HETE in the hypoxia-induced activation of $\mathrm{Ca}^{2+}$-activated $\mathrm{K}+$ channel currents in rat cerebral arterial muscle cells. Am. J. Physiol. Heart Circ. Physiol. 294: H107-H120.

Harder DR, Gebremedhin D, Narayanan J, Jefcoat C, et al. (1994). Formation and action of a P-450 4A metabolite of arachidonic acid in cat cerebral microvessels. Am. J. Physiol. 266: H2098-H2107.

Higgins JP, Thompson SG, Deeks JJ, and Altman DG (2003). Measuring inconsistency in meta-analyses. BMJ 327: 557-560.

Karpinos AR, Roumie CL, Nian H, Diamond AB, et al. (2013). High prevalence of hypertension among collegiate football athletes. Circ. Cardiovasc. Qual. Outcomes 6: 716-723.

Kikuta Y, Kusunose E, and Kusunose M (2000). Characterization of human liver leukotriene B(4) omega-hydroxylase P450 (CYP4F2). J. Biochem. 127: 1047-1052.

Lasker JM, Chen WB, Wolf I, Bloswick BP, et al. (2000). Formation of 20-hydroxyeicosatetraenoic acid, a vasoactive and natriuretic eicosanoid, in human kidney. Role of Cyp4F2 and Cyp4A11. J. Biol. Chem. 275: 4118-4126.

Li M, Wang H, Liu JL, Wang LJ, et al. (2013). Association of rs2108622 polymorphism of CYP4F2 gene and essential hypertension in the Northern Han Chinese. J. Cardiov. Pulmo. Dis. 32: 538-543.

Miyata N, Seki T, Tanaka Y, Omura T, et al. (2005). Beneficial effects of a new 20-hydroxyeicosatetraenoic acid synthesis inhibitor, TS-011 [N-(3-chloro-4-morpholin-4-yl) phenyl-N'-hydroxyimido formamide], on hemorrhagic and ischemic stroke. J. Pharmacol. Exp. Ther. 314: 77-85.

Roman RJ (2002). P-450 metabolites of arachidonic acid in the control of cardiovascular function. Physiol. Rev. 82: 131-185.

Sontag TJ and Parker RS (2002). Cytochrome P450 omega-hydroxylase pathway of tocopherol catabolism. Novel mechanism of regulation of vitamin E status. J. Biol. Chem. 277: 25290-25296.

Ward NC, Tsai IJ, Barden A, Van Bockxmeer FM, et al. (2008). A single nucleotide polymorphism in the CYP4F2 but not CYP4A11 gene is associated with increased 20-HETE excretion and blood pressure. Hypertension 51: 1393-1398.

Yousif MH, Benter IF, Dunn KM, Dahly-Vernon AJ, et al. (2009). Role of 20-hydroxyeicosatetraenoic acid in altering vascular reactivity in diabetes. Auton. Autacoid Pharmacol. 29: 1-12.

Zhang LN, Ji LD, Fei LJ, Yuan F, et al. (2013). Association between polymorphisms of alpha-adducin gene and essential hypertension in Chinese population. Biomed. Res. Int. 2013 2013: 451094. 
Zhang LX, Yang J, Shen FF, and Wang DW (2010). Association between the G20597A variant of CYP4F2 gene and essential hypertension. J. Chin. Phys. 12: 27-29.

Ziv-Gal A, Gallicchio L, Miller SR, Zacur HA, et al. (2012). A genetic polymorphism in the CYP19A1 gene and the risk of hypertension among midlife women. Maturitas 71: 70-75. 